\title{
AUGMENTED LEARNING: AN E-LEARNING ENVIRONMENT IN AUGMENTED REALITY FOR OLDER ADULTS
}

\author{
Sergio Cicconi, Maurizio Marchese \\ Dept. Information Engineering and Computer Science - University of Trento (ITALY)
}

\begin{abstract}
Studies on topics such as active ageing or health and wellbeing show that older adults want to remain healthy and active as they age. Nowadays, new technologies guarantee older adults longer and healthier lives, but do not really facilitate more social aspects of their lives. In a world where social relationships, public and private activities, or entertainment are based on the use of technology, older adults lacking technological knowledge risk social isolation. They will find it progressively more difficult to use all the public and private e-services necessary to maintain an active and socially integrated life. The goal of our research is to help older adults to cope with their technological illiteracy. In this paper we present our work on an innovative learning environment specifically tailored for older adults, easily accessible without any previous knowledge of technology, and capable of delivering educational material on technology and, particularly, on e-services. We use the technology available in the field of augmented reality, so that the learning environment an immersive, 3-D and fully interactive environment, capable of providing older adults with the knowledge on ICTs and ICT tools they need to become active and integrated citizens of our technological society.
\end{abstract}

Keywords: augmented learning, augmented reality, e-learning, learning for older adults.

\section{INTRODUCTION}

Older adults must deal with many problems due to ageing: their physical and mental conditions tend to deteriorate and they find it difficult to cope with many situations that in younger age they could easily control. Nowadays, Information and Communication Technologies (ICTs) can help older adults in many ways to slow down the effects of ageing and preserve their psycho-physical conditions for a longer time. However, ICTs also contribute to create new social problems in older adults, especially social isolation and loneliness. In a world more and more shaped by technology and digital communication, social relationships, public and private activities and services, entertainment and, overall, any form of exchange of information, will increasingly be based on the use of technology. So, older adults without ICTs literacy will find it progressively more difficult to maintain their social relations and activities, and feel that they are active citizens of the technological society. So, in order to avoid this new form of social isolation, the research has to find ways to provide older adults with knowledge on the use of computer and, more in general, on ICTs and ICT tools.

In this paper, we present our research on the design and development of an innovative form of elearning, specifically designed for older adults, that could provide a contribution in solving the outlined problem of social isolation. Particularly, we have designed and developed a learning environment using augmented reality. The learning environment is an immersive, 3-D and fully interactive environment, capable of easily introducing older adults to the knowledge on ICTs and ICT tools they need to be integrated and active in e-society.

\subsection{Older Adults and Active Ageing}

Researches and Governmental Institutions agree on the fact that, all over the world, there is a significant increase in lifespan, and the number of people who are 65 or older is constantly growing. This phenomenon is becoming so evident, and has so many economic and social consequences, that can no longer be neglect [1]. With age, many physical, and mental problems arise. According to the World Health Organization (WHO) [2], health problems in old age may be a consequence of factors such as poor nutrition, physical inactivity and bad habits, which may lead to several chronic diseases. However, these bad health conditions might also be caused by social problems [3], especially loneliness and social isolation [4].

Social isolation is not uncommon among older adults, and is often caused by impaired physical functioning, which might limit the older adults' ability to move and prevent them from having social interactions. So, older adults must rely on their social networks (family, friends) [5]. Such networks 
provide assistance and, at the same time, prevent from social isolation. However, nowadays, older adults' social networks tend to shrink and lose their supportive role. Furthermore, social services such as residential care - provide no practical support, if compared with the one that peers and relatives provide [6]. As a consequence, older adults easily feel lonely and socially isolated. And this feeling of loneliness is dangerous, as it might trigger many severe physiological and mental issues [7]. The existence of so many health problems in older population will have an important impact on the societies of the near future. The increasing longevity, without an adequate increment of older adults health conditions, will lead to a greater demand in health services, and consequently to higher costs for public institutions. Therefore, researches and policy makers have urged the development of specific strategies for the wellbeing of older adults [5], [8], [9], [10], [11].

The idea behind this view is "Active Ageing", which has been defined the first time in 2002 by the WHO [12]. Active Ageing refers to "the process of optimizing opportunities for health, participation and security, in order to enhance quality of life and wellbeing as people age" [1]. The European Commission has presented an agenda that proposes specific norms for active ageing [1]. At the same time, researchers have tried to identify the needs of older adults, and to find the ways to best help them, so to make their lives healthier, more active, enjoyable and independent. Within the active ageing context, there is one topic-area relevant for our research: learning, and particularly, learning of Information and Communication Technologies (ICTs).

\subsubsection{Older Adults and Learning}

Despite the common opinion, older adults are still capable to learn [13]. Various studies [14], [15], [16], [17] show that older adults learning can deliver many social, mental and physical benefits: not only can learning decrease older adults sense of isolation and loneliness, and enhance their personal and community wellbeing, but it can also can reduce their dependency on government-funded social services. Certainly, the learning interests of older adults differ from those of younger adults. Older adults are mainly interested in learning solutions to practical problems of real-life contexts [18]. Of course, there are biological changes that lead to memory decreases as people age [19]. Nonetheless, in order to learn new information, older adults usually cope with their memory loss by relating new information to previous knowledge or to their personal experience [20].

\subsection{E-learning and Augmented Learning}

"E-learning is a combination of methods, structures and networked electronic tools orchestrated into systems that bring about, or are intended to bring about, learning" [21]. Overall, e-learning studies can be focused on three principal research areas [22]: (1) users, interacting with e-learning systems; (2) technologies, enabling the direct or indirect interaction of the different groups of users; (3) learning theories and pedagogical practices.

In the literature, we find four learning theories considered the major and most influential pedagogical approaches on learning: Behaviorism and Cognitivism, both developed during the first half of the 20th century, and Constructivism and the On-line Collaborative Learning theory, developed in more recent years, and perhaps more capable of accounting for the emergence of technology in everyday life [21], [23], [24], [25]. Of course, the above theories on learning are not the only ones available. In recent years, as on-line learning and technology-based teaching have evolved, many new theories of learning are emerging [22], [26]. Given the range of learning and teaching styles, the potential ways technology can be implemented, and the ways in which educational technology itself is constantly changing, no single theory seems capable of accounting for all possible e-learning experiences. So, it is reasonable to think that different theories will continue to co-exist, and they will be used to satisfy the different needs of different people, using different technologies in different learning contexts.

Here, we consider some varieties of e-learning [27]: (a) standalone courses: self-paced courses taken by a solo learner; (b) learning games and simulations: learning by performing simulated activities that require exploration and lead to discoveries; (c) mobile learning: learning from the world while moving about in the world; (d) social learning: learning through interaction with a community of experts and fellow learners; (e) virtual-classroom courses: on-line classes structured much like a classroom course, with reading assignments, presentations, discussions via forums, synchronous on-line meetings, and other social media, and homework.

\subsubsection{Augmented Learning}

There is one more form of e-learning: Augmented Learning ( $A L)$, a form of standalone learning within Augmented Reality (AR) environments which provides users with 3-D, interactive, and, in some cases, 
immersive learning experiences [28]. Researchers started years ago to investigate the potential of AR in educational settings [26]. Many argue that fully working $A L$ environments deployed as $A R$ applications could really contribute to change, enrich, and improve the learning experience in many ways: by facilitating the learning of visual contents; or by encouraging the process of "learning-bydoing"; or by increasing the user's involvement in the process of learning; or by encouraging collaboration and social interaction; or by connecting the user's personal experience to the contents to be learned [29], [30], [31], [32], [33], [34], [35].The state of current research in AR for education can be still considered in its infancy [26] but, finally, AR is a mature technology, already available in the market. So, researcher can really start thinking about AR applications for education.

\subsection{Augmented Reality}

Augmented reality is an emerging form of experience in which the real world is enhanced (or augmented) by computer-generated content. AR allows digital content to be seamlessly overlapped and combined into our perceptions of the real world in real time [30], [36], [37]. The most evolved forms of AR create a full-rounded immersive experience involving all senses, and add rich and meaningful extra-worlds to the real world (see Fig. 1). Some recent AR systems, actually leading the AR market (such as Microsoft HoloLens, Meta, or Magic Leap [38]) allow even the interaction between users and the virtual objects belonging to the Augmented Environments.

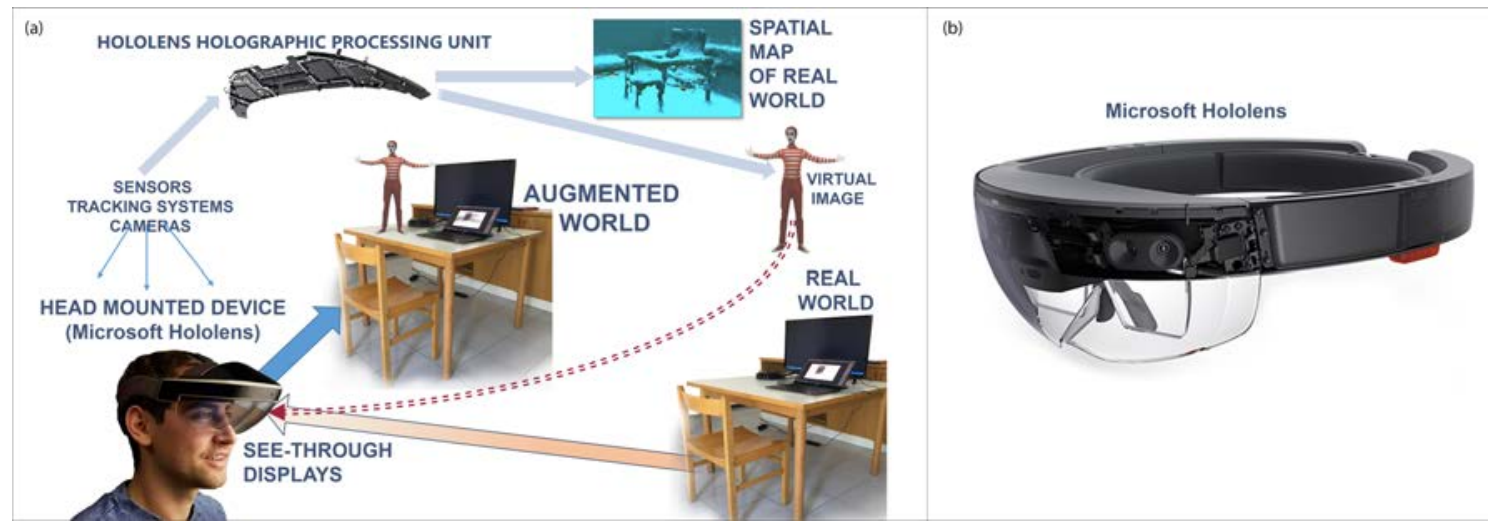

Figure 1: A conceptual diagram of an AR system (a) with a head-mounted device and see-through displays (b). The see-through displays allow the user to see the real world as if looking at it through a normal pair of glasses. Through sensors, tracking systems and cameras the device acquires information on the user's position and on the objects in the real world surrounding the user. Virtual objects are then generated in real time in the see-through displays, so that they are seamlessly integrated with the objects in the real world perceived by the user.

The idea of a device capable of displaying computer-generated objects overlaid and mixed with real objects was first devised during the Fifties [30], [39], but it was only during the Sixties that actual devices capable of displaying simple AR environments were created. However, the technologies used to develop these devices were too primitive to be able to produce real experiences of augmented reality. From the Seventies, up to the end of the Nineties, research on AR was mostly focused on the development of new technologies related to AR. But, again, technology was not good enough, so the devices created in most cases remained experimental devices with no concrete application in the real world. The only exception to this situation was, perhaps, the development of some very expensive and highly specialized devices for professional applications, such as maintenance and repair of complex equipment and medical visualization [40]. Only the rapid growing in microprocessors performance, and the recent progresses in micro-chips and sensors miniaturization, in display techniques, or in techniques for tracking did allow AR researchers to finally open the doors of their labs and make AR devices accessible to the masses. Today, AR is no longer an "emerging" technology, and even though it cannot yet be considered a flawless technology [40], it's not difficult to think that in a few years will become a powerful and familiar tool in everyday life.

\subsubsection{Devices and Application for Augmented Reality}

The most common devices [39], [41], [42] used to deliver AR content are: (1) mobile devices: AR mobile applications provide a non-immersive augmented experience by creating the virtual contents and mixing them with the real world captured with the device mobile camera; (2) wearable devices: 
Users mount this type of devices, also called head-mounted displays (HMDs), on their heads, with the device see-through displays in front of their eyes. The AEs are projected on the displays, so to superimpose virtual content onto some portions of the perceived real world. In this case, the devices also allow full 3D, interactive and immersive experiences.

Many AR consumer applications for Android or iOS mobile devices are already available, and the market of mobile applications is constantly growing. However, as more models of HMDs become available and their prices decrease, also applications for HMDs are becoming more affordable and popular. For example, we find many professional apps for AR HMDs [30], [40], [43], [44], especially in high-tech fields such as medicine [45], robotics [46], industry automotive [47], architecture [48], advertising and marketing, visual arts [49], entertainment, military air crafting, manufacturing.

As for AR applications in the field of education, the research is just in its infancy, so it is difficult to find applications devoted to explore educational settings. However, the field of AL shows a great potential. For several years, e-learning seemed mostly focused on the Web and the online courses for distant education. Perhaps, in the near future, augmented learning will be able to take education away from the Web and move it into a new reality which will be enriched by augmented reality.

\subsection{E-society and E-services}

According to a recent report commissioned by eBay [50], in 2014 more than $90 \%$ of U.S. small and medium-sized businesses used eBay platform to export goods internationally. In 2009 , only $10 \%$ were exporting. This means that eBay, by using the Internet, has enabled businesses to become really global traders. And eBay is not the only provider offering such services. Also large e-service providers such as Google, Amazon, Alibaba and others enable small and medium-sized businesses to use their platforms to promote their business. In so doing, these big providers not only become able to sell any sort of product or service to an increasing number of customers everywhere in the world, but also boost the shift of traditional business toward electronic business. So, business companies, even those that do not want to join large service providers, trying to remain competitive, are somehow forced to move their business on-line.

Of course, U.S. is not the only country to move business services on-line. In many developed countries, the trend is the same: business companies, no matter where their base-country is, use the Internet to operate globally. And their services are cheaper, faster, and more reliable than old, regular, off-line services [51]. And non-business and public services undergo the same change as well: public services progressively become e-services. E-services offer national governments the promise of increased convenience, lower transacting costs, increased consumer choices, enhanced efficiency and effectiveness of the services being delivered to all citizens, and greater accessibility by eliminating space and time constraints [51]. So, Governments from the various developed countries are gearing up to transform traditional services into on-line services: government services become e-government services, healthcare services become e-health services, and so on. The progressive conversion of services into e-services marks the transition of our society into e-society. In an e-society social relationships, public and private activities, entertainment and, overall, any form of exchange of information, will increasingly be based on the use of electronic services.

\subsubsection{Older Adults in E-society}

The transformation of society into e-society has many evident economic and social benefits. However, the pervasiveness of e-services in e-society also raises a fundamental issue: e-services, in order to be used, need computer literacy. So, people lacking knowledge on ICTs will find it increasingly more difficult to use all the public and private e-services available to e-society members and will be excluded from any form of e-social interaction. In short, they will be excluded from e-society. Clearly, those most at risk of ending up excluded from e-society are, again, those older adults who did not have many opportunities to learn new technologies during their working life. Once they are retired, they find it even more difficult to acquire technological literacy, and so they find themselves unable to cope with e-society. It is true that the portion of older adults using ICTs is increasing; for example, the Italian Institute of Statistics (ISTAT) [52] states that in Italy, in recent years, the number of older adults using the computer and the Internet tripled. But it is still poorer compared with younger adults [53].

In an earlier section of this paper, we saw that social isolation and loneliness were two major sources of mental and physical problems in older adults. Now, we see that the same society that urges to find technological solutions to the problem of social isolation in older adults, also creates, because of technology, a new possible form of social isolation. Without ICTs literacy, older adults will find it difficult, when not impossible, to use technologies to maintain their mental life active. Moreover, they 
will find progressively harder to "feel connected with the world" and to maintain their social relations in a world that is more and more permeated by technology. So, as we already said, it becomes important to address this problem within the active aging context; it becomes important to look for new strategies for making knowledge on ICTs more accessible to older adults, so to reconnect them with the world.

We also saw that learning, in general, can provide older adults with many social, mental and physical benefits. If we now take also into account what we just said on older adults and e-society, we can easily see that learning focused on ICTs can have on older adults even more beneficial effects. As some studies suggest [54], [55], knowledge on ICTs makes older adults feel connected again with the world, integrated again in society, and part of the "human race".

So, believing that a learning environment (LE) designed for older adults and capable of easily introducing them to ICTs and e-services could provide a contribution in solving the problem of social isolation previously outlined, we started working on the design of an innovative form of LE.

\section{THE DESIGN OF THE AUGMENTED LEARNING ENVIRONMENT}

We worked on the design and development of a new LE using AR technologies, and we were also able to create a working prototype of the LE displaying the features of augment environments we previously described. The actual prototype is an AR application running on Microsoft HoloLens and capable of generating an immersive, 3-D and interactive environment. Once completed, the LE will be capable of delivering learning modules (LMs) on a variety of topics dealing with ICTs and ICT tools, and particularly with e-services. During the design of the LE, we follow the well-known Software Engineering practice of "separation of concerns" [56] and we thrived to keep as separate as possible the design of the augmented environment (AE) from the design of the LMs. This has allowed us, during the design of the LE, to freely explore all the features and possibilities offered by AR without any constriction or limitation imposed on the design by the learning contents to be used in the LMs, or by the features of the real users of the LE.

Only after the completion of a first draft of the design of the $A E$ and the development of a working prototype, will we start dealing with the design of the LMs. Finally, once the design of the LMs will be completed, we will go through a process of fine-tuning of the overall design of the LE: we will take into account the features of the LE ideal users, and will adapt the interfaces and features of the LE in order to maximize the usability of the LE for older adults and make their learning experience as useful and enjoyable as possible.

\subsection{Design Process: the Augmented Environment}

As we said, during the design of the $A E$, we wanted to take full advantage of the features of $A R$ environments to create an $A E$ capable of expressing its full potential only as an AR application for HMDs [29], [30], [33]. Particularly, we required our AE to have the following, fundamental features: (a) must be able to seamlessly combine the real world and the virtual world; (b) must be interactive in real-time; (c) must be fully 3-D; (d) must be immersive.

With the above in mind, we defined:

1 The general features of the AE (definition of a general environment, possible sub-division of the general environment into sub-spaces, definition of learning modules, definition of the interface(s) allowing the user to navigate throughout the AE);

2 the rules on how the virtual objects interact (with other objects, with the user, with the real world);

3 the features of a virtual helper/assistant, which will help the user on different aspects of her learning experience;

Overall, we also wanted our LE to have some extra-features. Although they are not essential to define AEs, they should contribute to increase the user's comfort and sense of familiarity with the augmented world, and make the learning experience easier and more enjoyable:

1 the $A E$ should be designed in such a way that it does not require users to know the technology involved in the creation of the $\mathrm{AE}$;

2 the $\mathrm{AE}$ should allow an easy access to its objects and contents (interfaces allowing orientation and navigation of the virtual environment should be easy to understand and use); 
3 the AE should be easily adaptable to the specific needs of different users (i.e., if necessary, hand-gesture commands controlling interaction can be replaced by vocal commands), so to allow the use of the $A E$ also to users with particular impairments;

4 Overall, the AE should be designed to: (a) facilitate the learning of visual contents; (b) encourage the process of "learning-by-doing"; (c) increase the user's involvement and enjoyment; (d) connect the user's personal experience to the contents to be learned.

\subsection{Design Process: the Learning Modules}

This is an ongoing project, and the design of the LMs is still in progress. As we said, before focusing on the design of LMs, we wanted to have a working prototype of the general AE as described above, so to have a firsthand experience of the AE and to test the effectiveness of the first draft of the design.

\subsubsection{Looking for Design Principles: Features of E-learning On-line Courses}

Before working on the design of the LMs, we will examine the structures and the organization of the contents of a few open on-line courses (MOOCs) [57], [58], such as Coursera, edX, Udemy, Udacity. Such analysis will provide us with some valuable hints on how to design the learning experience we want to create with our LE. Obviously, the design principles we might find during our analysis will need to be adapted to the different medium they are used in, that is, AR. Particularly, we want to identify:

- the most common learning elements providing users of on-line courses with what should be considered as a good learning experience (syllabus, calendar, videos, lectures, collaborative and social features, homework management, grades management, resources, tests, menu, links, etc.);

- the micro- and macro-organizations of the above learning elements (learning activities, learning objects, lessons, modules, chapters, seminars, etc.).

- usability/accessibility features [59], [60], [61] (navigation tools, text alternatives, time-based media alternatives, adaptable contents, distinguishable contents, enough time to get contents, easily navigable readable, predictable, with input assistance, compatible, etc.).

\subsubsection{Contents of the Learning Modules}

The content of the LMs will mostly deal with a few important public and private e-services (such as egovernment, e-health, home-banking, social media, e-commerce, e-entertainment) accessible through the Web. However, since our target users lack of knowledge on ICTs, we need to provide them with at least a basic background knowledge on the usage of the Web. To identify and select the content to be used with the LMs, we will rely on a few introductory books or manuals on ICTs and e-services [62], [63], [64]. We also plan to organize a focus group with older adults with computer literacy in order to identify, together with the participants, the topics that, according to their experience, they believe to be most relevant to use in an introductory course on ITCs and e-services.

\subsubsection{The Design of the Learning Modules}

For the design of the LMs, we will mostly rely on the learning design methodologies described in [23], [27], [65], [66], [67]. Particularly:

1 we want to segment the contents on basic ICTs and e-services into basic pieces of learning content, or "learning units"; each learning unit: (a) will contain the information on what to teach in one learning activity; (b) will also contain one or more mini-tests to verify that the user has learned the piece(s) of learning content defined in the learning unit;

2 we want define the rules according to which the learning units can be combined together to create new learning units with a higher level of complexity (e.g., topics, lessons);

3 we want to define the whole learning experience with the LMs on ICTs and e-services as a hierarchical structure of learning units with different levels of complexity.

\subsection{Design Process: Fine-Tuning the Design for the Target Users}

Once we will have completed a first draft of the general design of the AE and the LMs, we will make further changes to this design so to tailor the LE for older adults. This means to identify older adults' needs, interests and capabilities, so to be able to adjust the design accordingly. However, we do not need a too complex definition of "older adults"; we only need to identify those psycho-physical or 
behavioral traits typical in older age that impose some formal or structural change in the design. Particularly, we will examine the literature on older adults looking for valuable information on:

Psycho-physical traits: older adults might suffer from some psycho-physical impairments; we need to take such disabilities into account, so that content can be delivered in such a way to minimize the disadvantages due the possible impairments. For example, if we know from literature that a progressive loss of sight or hearing occurs in older age, we must provide the LE with alternative navigation systems (i.e., textual menus and vocal command) or different ways of delivering contents (i.e., via images and via oral narration), so that one system/way can replace the other when necessary.

Education level \& Digital knowledge: to select the most adequate language to use during the learning experience, or the level of in-depth of the content, or the topics that can satisfy the older adults needs and interests, we need to have information on the older adults general level of education and on the knowledge they have on the use of computers, on ICTs and of ICT tools.

\section{THE PROTOTYPE OF THE AUGMENTED ENVIRONMENT}

We used a draft of the design of the $A E$ to develop a working prototype of the $A E$ which, however, does not yet include the LMs. The prototype is an AR application running on Microsoft HoloLens, and has been developed using the game engine Unity 2018 [68], and the programming language C\#. The prototype needs further development, but it already shows all the main features of AR environments:

- The general features of a functioning AR environment: scanning and understanding the real environment surrounding the user; identification of real surfaces to be used with augmented content (holograms);

- Several augmented sub-environments: login area, main hall, training area, one learning module (its general structure and features, but without contents):

- the main interfaces allowing assistance and navigation (help panels, tool bars);

- a virtual assistant (Fig. 2) with synthetic voice, gestures, lip synch, and facial expressions and capable of interacting with the user and guiding her throughout the entire learning experience;

Each of the areas defined above is fully featured with an help panel, working interfaces for navigation and interaction with the already existing holograms.

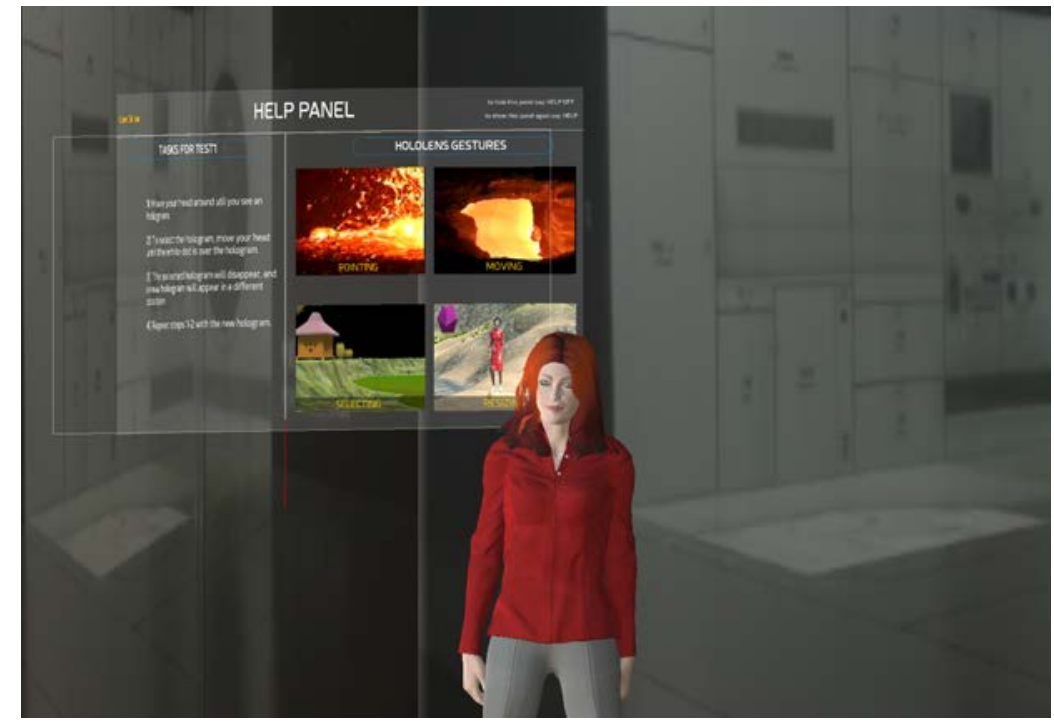

Figure 2: the virtual assistant explaining the use of the help panel.

\section{CONCLUSIONS}

The LE has been designed for a particular purpose, that is, to help older adults to cope with their technological illiteracy and to overcome their social isolation. Once completed, such LE could become a possible alternative to existing online courses, particularly if we think that these courses are usually 
not tailored for older adults[13], [69] and that, contrarily to what happens with our LE, they require at least some basic knowledge on ICTs in order to be used.

When we will be able to test the prototype with groups of older adults, we will have the opportunity to verify our working hypothesis, according to which, it should be easy, even for older adults, to use our LE and, more in general, augmented reality technology. Moreover, we will also have the opportunity to further explore the complex relationship between older adults and new technologies and, particularly, AR: are older adults so willing to accept a technology that mixes the real world with a fictional and virtual world? How do older adults feel about having a somehow awkward device on their head, which, in addition, alters their perceptions? What is their reaction to dealing with holograms?

Finally, the separation we tried to keep while designing the LE between the design of the AE and the design of the LMs has important consequences: it makes it possible to think of a use of our LE with a wider and more general scope than the one defined so far for our project. In fact, because of such separation, it become possible to introduce substantial changes to the contents of the LMs without affecting the general augmented environment hosting the LMs. And this opens up the possibility of using the same general LE in different settings, with different contents and for different types of users.

\subsection{Future Work}

We plan to add the LMs and their learning contents to the prototype, so to have a fully working prototype of LE. Also, we plan to improve the virtual assistant and make it more capable of interacting with the user, since we believe that a more interactive assistant could greatly increase the quality of the learning experience. Finally, we intend to use the LE with groups of older adults to test the LE, and to explore the impact AR has on older adults.

\section{ACKNOWLEDGEMENTS}

This work was partially supported by a mobility scholarship at the Nara Institute of Science and Technology (NAIST) - Japan, in the frame of the Erasmus Mundus Action 2 Project TEAM, funded by the European Commission. We would also like to thank prof. Hirokazu Kato, director of the Interactive Media Design Lab at NAIST, for his help on many AR related topics presented in this paper.

\section{REFERENCES}

[1] R. Fernàndez-Ballesteros, J. M. Robine, A. Walker, and A. Kalache, "Active aging: a global goal," Curr. Gerontol. Geriatr. Res., vol. 2013.

[2] "World Health Organization," 2017. Retrieved from: http://www.who.int/ageing/en/

[3] E. Y. Cornwell and L. J. Waite, "Social Disconnectedness, Perceived Isolation, and Health among Older Adults," J. Health Soc. Behav., vol. 50, no. 1, pp. 31-48, 2009.

[4] G. C. Wenger, R. Davies, S. Shahtahmasebi, and A. Scott, "Social isolation and loneliness in old age: review and model refinement," Ageing Soc., vol. 16, no. 3, pp. 333-358, 1996.

[5] K. B. Adams, S. Leibbrandt, and H. Moon, "A critical review of the literature on social and leisure activity and wellbeing in later life.," Ageing Soc., no. 31, pp. 683-712, 2011.

[6] C. Stephens, F. Alpass, A. Towers, and B. Stevenson, "The effects of types of social networks, perceived social support, and loneliness on the health of older people: Accounting for the social context," J. Aging Health, vol. 23, no. 6, pp. 887-911, 2011.

[7] L. C. Hawkley and J. T. Cacioppo, "Loneliness matters: a theoretical and empirical review of consequences and mechanisms," Ann. Behav. Med., vol. 40, no. 2, pp. 218-227, 2010.

[8] L. Foster and A. Walker, "Gender and active ageing in Europe," Eur. J. Ageing, vol. 10, no. 1, pp. 3-10, 2013.

[9] L. Foster and A. Walker, "Active and successful aging: A European policy perspective," Gerontologist, vol. 55, no. 1, pp. 83-90, 2014.

[10] P. Stenner, T. McFarquhar, and A. Bowling, "Older people and 'active ageing': Subjective aspects of ageing actively," J. Health Psychol., vol. 16, no. 3, pp. 467-477, 2011. 
[11] A. Walker and T. Maltby, "Active ageing: A strategic policy solution to demographic ageing in the European Union," Int. J. Soc. Welf., vol. 21, no. s1, 2012.

[12] W. H. Organization, "Active ageing: A policy framework," 2002. Retrieved from: http://www.who.int/ageing/publications/active_ageing/en/

[13] S. Sanchez-Gordon and S. Luján-Mora, "Web accessibility of MOOCs for elderly students," in information technology based higher education and training (ITHET), 2013 International Conference on, 2013, pp. 1-6.

[14] J. Field, "Adult learning, health and wellbeing-changing lifes," Adult Learn., 2011.

[15] M. Formosa, "Renewing Universities of the Third Age: Challenges and visions for the future," Recer. Rev. Pensam. $i$ anàlisi, no. 9, pp. 171-196, 2009.

[16] S. Merriam and Y. Kee, "Promoting community wellbeing: The case for lifelong learning for older adults," Adult Educ. Q., vol. 64, no. 2, pp. 128-144, 2014.

[17] J. Balatti and I. Falk, "Socioeconomic contributions of adult learning to community.," Adult Educ. Q., vol. 4, no. 52, pp. 281-298, 2002.

[18] H.-M. Huang, "Toward constructivism for adult learners in online learning environments," Br. J. Educ. Technol., vol. 33, no. 1, pp. 27-37, 2002.

[19] S. Merriam, "Andragogy and self-directed learning: Pillars of adult learning theory," New Dir. adult Contin. Educ., vol. 2001, no. 89, pp. 3-14, 2001.

[20] K. Cercone, "Characteristics of adult learners with implications for online learning design," AACE J., vol. 16, no. 2, pp. 137-159, 2008.

[21] J. Dron and T. Anderson, "The Future of E-Learning," in SAGE Handbook of E-learning Research, 2nd ed., C. Haythornthwaite and et. al., Eds. 2016.

[22] M. Aparicio, F. Bacao, and T. Oliveira, "An e-learning theoretical framework," J. Educ. Technol. Soc., vol. 19, no. 1, 2016.

[23] A. W. (Tony) Bates, Teaching in a digital age. 2015. [E-Reader Version] https://opentextbc.ca/t eachinginadigitalage/.

[24] L. Harasim, Learning Theory and Online Technologies. Routledge, 2012.

[25] D. H. Schunk, Learning Theories: An Educational Perspective (6th Edition). Pearson, 2011.

[26] J. Bacca, S. Baldiris, and et. al., "Augmented reality trends in education: a systematic review of research and applications," J. Educ. Technol. Soc., vol. 17, no. 4, p. 133, 2014.

[27] W. Horton, E-learning by design, 2nd edition. 2012.

[28] J. Chan, T. Pondicherry, and P. Blikstein, "LightUp: an augmented, learning platform for electronics," in Proceedings of the 12th International Conference on Interaction Design and Children, 2013, pp. 491-494.

[29] M. Akcayir and G. Akcayir, "Advantages and challenges associated with augmented reality for education: A systematic review of the literature," Educ. Res. Rev., vol. 20, pp. 1-11, 2017.

[30] R. Azuma, "A survey of augmented reality," Presence Teleoperators virtual Environ., vol. 21, no. 6, pp. 34-47, 1997.

[31] C. Lai and Y. Chu, "Increasing the Learning Performance via Augmented Reality Technology," in International Symposium on Emerging Technologies for Education, 2016, pp. 58-64.

[32] F. Liarokapis, P. Petridis, P. F. Lister, M. White, and others, "Multimedia augmented reality interface for e-learning," World Trans. Eng. Technol. Educ., vol. 1, no. 2, pp. 173-176, 2002.

[33] B. Ralhan, "AR: Transform your surroundings to learn anytime, anywhere!," 2017.

[34] F. Rose, "The Power of Immersive Media," Strateg. Bus., 2015.

[35] M. E. C. Santos, A. Chen, T. Taketomi, G. Yamamoto, J. Miyazaki, and H. Kato, "Augmented reality learning experiences: Survey of prototype design and evaluation," IEEE Trans. Learn. Technol., vol. 7, no. 1, pp. 38-56, 2014. 
[36] R. Azuma, "Location-Based Mixed and AR Storytelling," 2015.

[37] W. Barfield, "Wearable Computers and Augmented Reality: Musings and Future Directions." Fundamentals of Wearable Computers and Augmented Reality, Second Edition, London: CRI Press, pp. 3-11, 2015.

[38] A. Dakis, "What's the Difference Between HoloLens, Meta and Magic Leap." 2016.

[39] K. Kiyokawa, "Head-Munted Display Technologies for Augmented Reality," pp. 60-84, 2015.

[40] R. Azuma, "The Most Important Challenge Facing Augmented Reality," PRESENCE Teleoperators Virtual Environ., no. 00, 2016.

[41] B. Kress, "Optics for Smart Glasses, Smart Eyewear, Augmented Reality, and Virtual Reality Headsets," pp. 85-123, 2015.

[42] T. Starner, "Wearable Computing. Meeting the Challenge," pp. 13-29, 2015.

[43] S. C.-Y. Yuen, G. Yaoyuneyong, and E. Johnson, "Augmented Reality: An Overview and Five Directions for AR in Education,” J. Educ. Technol. Dev. Exch., vol. 4, no. 1, pp. 119-140, 2011.

[44] W. Barfield, Fundamentals of wearable computers and augmented reality. CRC Press, 2015.

[45] Z. Yaniv and C. A. Linte, "Applications of Augmented Reality in the Operating Room," pp. 485518, 2015.

[46] M. Sugimoto, "Augmented reality Human-Robot Interfaces toward Augmented Robotics," pp. 399409, 2015.

[47] V. Gay-Bellile, S. Bourgeois, D. Larnaout, and M. Tamaazousti, "Applications of Augmented Reality for the Automotive Industry," pp. 433-457, 2015.

[48] K. Behzadan Dong, "Recent Advances in Augmented Reality for Architecture, Engineering and Construction," pp. 331-398, 2015.

[49] V. Geroimenko, Augmented reality art: from an emerging technology to a novel creative medium. 2014.

[50] e-Bay, "2015 US Small Business Global Growth Report - A world of opportunity for every American Small Business," 2015. Retrieved from: https://goo.gl/aoTJzZ.

[51] J. Mou, D.-H. Shin, and J. F. Cohen, "Trust and risk in consumer acceptance of e-services," Electron. Commer. Res., vol. 17, no. 2, pp. 255-288, 2017.

[52] ISTAT, "Cittadini e nuove tecnologie," 2014. Retrieved from: http://www.istat.it/it/archivio/143073

[53] W. Rogers and A. Fisk, "Toward a psychological science of advanced technology design for older adults," Journals Gerontol. Ser. B Psychol. Sci. Soc. Sci., vol. 65, no. 6, pp. 645-53, 2010.

[54] V. Winstead et. al., "You can teach an old dog new tricks: A qualitative analysis of how residents of senior living communities may use the web to overcome spatial and social barriers," J. Appl. Gerontol., vol. 32, no. 5, pp. 540-560, 2013.

[55] B. Xie, "Older adults, computers, and the Internet: Future directions," Gerontechnology, vol. 2, no. 4, pp. 289-305, 2003.

[56] G. Booch, R. a. Maksimchuk, M. W. Engle, B. J. Young, J. Conallen, and K. a. Houston, ObjectOriented Analysis and Design with Applications. 2007.

[57] "The Best MOOC Platforms of 2017," 2017. Retrieved from: https://goo.gl/q3WBDp.

[58] A. Bozkurt, E. Akgün-Özbek, and O. Zawacki-Richter, "Trends and patterns in massive open online courses: Review and content analysis of research on MOOCs (2008-2015)," Int. Rev. Res. Open Distrib. Learn., vol. 18, no. 5, 2017.

[59] S. Krug, Don't make me think, Revisited: A common sense approach to web usability. Pearson Education India, 2014.

[60] J. Nielsen and H. Loranger, Prioritizing web usability. Pearson Education, 2006.

[61] W3C, "Web Content Accessibility Guidelines (WCAG) 2.0," 2008. Retrieved from: https://www.w3.org/TR/WCAG20/ 
[62] F. Tomasi, Metodologie Informatiche e Discipline Umanistiche. Carocci Editore, 2008.

[63] R. White and T. Downs, How computers work, 10th edition. Que Corp., 2014.

[64] L. Harper, "A Citizen's Guide to Open Government, E-Government, and Government 2.0," 2013. Retrieved from: https://goo.gl/WuEz2N

[65] J. Dirksen, Design for how people learn. New Riders, 2015.

[66] W. W. Lee and D. L. Owens, Multimedia-based instructional design: computer-based training, web-based training, distance broadcast training. John Wiley \& Sons, 2004.

[67] R. M. Gagne and L. J. Briggs, Principles of instructional design., 4th ed. Holt, Rinehart \& Winston, 1974.

[68] "Unity 2018." Retrieved from: https://unity3d.com/

[69] N. Dabbagh, "The online learner: Characteristics and pedagogical implications," Contemp. Issues Technol. Teach. Educ., vol. 7, no. 3, 2007. 